\title{
СТРЕСС И СТРЕСС-МЕНЕДЖМЕНТ В ДЕЯТЕЛЬНОСТИ УЧАСТКОВЫХ УПОЛНОМОЧЕННЫХ ПОЛИЦИИ
}

\section{STRESS AND STRESS MANAGEMENT IN THE ACTIVITIES OF DISTRICT POLICE COMMISSIONERS}

\section{E. Chernobrodov \\ N. Galkina}

Summary: The activities of district police commissioners involve constant interaction with other people: immediate supervisors, colleagues, minors, people in difficult life situations, and others. This communication can provoke conflict situations, which in turn leads to the experience of stress by the district police officers. Currently, the psychological literature presents a wide variety of methods aimed at preventing stress. The authors propose a relatively new direction - "stress management" - as another method of prevention. The article describes the psychological features of the professional activity of district police officers, defines the concepts of "stress" and "stress management", presents the results of the study of stress factors in the professional activity of district police officers, reveals the possibilities of using stress management.

Keywords: stress, stress management, stress factors, stress management, self-regulation, self-recovery.

\author{
Чернобродов Евгений Романович \\ К.ncх.н., Дальневосточный юридический институт \\ МВД России, г. Хабаровск \\ erch70@rambler.ru \\ Галкина Наталья Юрьевна \\ K.nсх.н., доцент, Дальневосточный юридический \\ институт МВД России, г. Хабаровск \\ galkina55@list.ru
}

Аннотация: Деятельность участковых уполномоченных полиции подразумевает постоянное взаимодействие с другими людьми: непосредственными начальниками, коллегами, несовершеннолетними, людьми, находящимися в трудной жизненной ситуации и другими. Это общение может провоцировать конфликтные ситуации, что в свою очередь приводит к переживанию участковым уполномоченным полиции стресса. В настоящее время в психологической литературе представлено большое многообразие методов, направленных на профилактику стресса. Авторами предлагается в качестве еще одного метода профилактики относительное новое направление «стресс-менеджмент». В статье описываются психологические особенности профессиональной деятельности участковых уполномоченных полиции, дается определение понятиям «стресс» и «стресс-менеджмент», представлены результаты проведенного исследования стресс-факторов в профессиональной деятельности участковых уполномоченных полиции, раскрываются в0зможности использования стресс-менеджмента для профилактики данного социально-психологического явления участковыми уполномоченными полиции, дается характеристика основных этапов управления стрессом и методов, используемых на каждом этапе.

Ключевые слова: стресс, стресс-менеджмент, стрессогенные факторы, управление стрессом, саморегуляция, самовостановление.

ситуацию, не терять способности к целенаправленной рефлексивной деятельности. Это позволит ему проанализировать и оценить происходящее, подобрать оптимальный способ коррекции ситуации, своего поведения и (или) состояния, тем самым, выйти из состояния стресca.

Цель статьи - определение психологических подходов к преодолению стрессовых ситуаций участковыми уполномоченными полиции.

Деятельность УУП является одной из самых сложных профессий в современном обществе, направленной на обеспечение общественного порядка, выявление причин и условий, способствующих совершению преступлений, и принятие мер к их устранению на обслуживаемой территории.

Психологическими особенностями профессиональной деятельности участкового уполномоченного по- 
лиции являются: нормативно-правовая регламентация; наличие властных полномочий; необходимость принятия решений правового характера; экстремальная обстановка производства процессуальных действий; часто ненормированный рабочий график, временной дефицит; постоянное взаимодействие с различными категориями граждан, с преобладающим криминогенным контингентом; пристальное внимание со стороны органов прокуратуры и общественности.

Все вышеперечисленные факторы в своей совокупности приводят к переживанию УУП стресса - ответной реакции психики человека на переживаемые им сильные положительные и отрицательные эмоции, а также перенапряжение, с ними связанные. Стресс является нормальной частью человеческой жизни и необходимым в определенных количествах, так как он заставляет думать (активизирует познавательные процессы в целом), искать выход из проблемы (включение механизмов волевого поведения). Но если стрессоров становится слишком много, человек начинает уставать, терять силы и способность находить решение повседневных задач.

В целях объективной оценки стрессогенности профессиональной деятельности участковых уполномоченных, авторским коллективом применен метод экспертных оценок. Данный метод базируется на основе интуитивно-логического анализа исследуемых проблем на основе опроса высококвалифицированных специалистов. Надёжность оценок и решений, принимаемых на основе суждений экспертов, достаточно высока.

В экспертном опросе приняли участие 204 сотрудника подразделений участковых уполномоченных полиции УМВД России по Хабаровскому краю из 7 городов (Амурск, Бикин, Вяземский, Комсомольск-на-Амуре, Николаевск-на Амуре, Советская Гавань, Хабаровск) и 13 муниципальных районов Хабаровского края (Амурский, Аяно-Майский, Бикинский, Верхнебуреинский, Вяземский, Комсомольский, имени Лазо, Николаевский, Советско-Гаванский, Солнечный, Тугуро-Чумиканский, Ульчский, Хабаровский). Эксперты составили две группы: Группа экспертов-руководителей (ГЭР) и Группа экспертов-участковых (ГЭУ).

Группа экспертов-руководителей (ГЭР): 21 чел. Средний стаж в ОВД: 15 лет. Средний стаж в подразделении участковых уполномоченных полиции: 8 лет. Высшее юридическое образование имеют 90.4\%. Результаты опроса экспертов позволил определить несколько характеристик служебной деятельности способных вызвать состояние стресса.

Установлено, что наибольшая затрата рабочего времени связана с «работой с документами/отчеты, справки, рапорта и т.п.»; «совещаниями». Данный вид деятельности требует от сотрудника внимательности, организо- ванности, грамотности, аккуратности, соблюдения требований по стилистики и оформлению при подготовке документов. Стрессором (то, что приводит к стрессу) здесь выступает острый дефицит времени на подготовку справок, отчетов, рапортов, планов и т.п.

В организационно-управленческой подструктуре профессиональной деятельности, несомненно, присутствует такая форма деятельности как совещание (планирование и подведение итогов работы, рассмотрение текущей повестки дня по актуальным вопросам, требующих сбора личного состава подразделений). Опрос показал, что видами профессиональной деятельности, способными вызывать негативные переживания являются: «работа с документами, подготовка отчётов», «работа не по своему направлению», «участие в совещаниях», «планирование рабочего дня».

ГЭР актуальными проблемами в организации деятельности видят в: «некомплекте кадров в подразделениях УУП», «большом объёме документооборота», «недостаточном уровне материально-технического обеспечения (канцелярские товары, компьютеры и т.п.)», «нехватке служебного транспорта», «удалённости административных участков». Каждый в отдельности фактор способен стать стрессором (см. Таблицу 1).

ГЭР считают (около 60\% опрошенных), что «назначение на должности участковый уполномоченный полиции сотрудников женского пола на результаты службы» не влияет. Лишь 14\% опрошенных уверены, что «женщинам- участковым гораздо сложнее выполнять свои обязанности». Только $10 \%$ респондентов считают профессию участкового уполномоченным сугубо мужской. Следует отметить, что игнорирование гендерного аспекта способно помешать объективной оценке психологического состояния участкового уполномоченного полиции - женщины.

Женщины-полицейские в отношении показателей физического напряжения, соматизации, а также показателей здоровья, демонстрируют более высокий уровень стрессового напряжения по сравнению с полицейскимимужчинами. «Анализ накопленного за рубежом научного и прикладного опыта указывает на необходимость более пристального внимания к изучению вопроса о влиянии гендерных различий на восприятие стрессогенных факторов и выраженность профессионального стресса у сотрудников правоохранительных органов» [3].

Около 70\% членов ГЭР считают изучение проблемы управлением профессиональным стрессом значимой для результатов служебной деятельности и готовы к прохождению курсов повышения квалификации по стресс-менеджменту (управлению стрессами) в работе руководителя. 
Группа экспертов-участковых (ГЭУ): 183 чел. Средний стаж в ОВД: 9 лет. Средний стаж в подразделении участковых уполномоченных полиции: 7 лет. Высшее юридическое образование имеют 65,5\%, высшее техническое образование $16 \%$, высшее педагогическое образование $6,5 \%$.

По мнению ГЭУ больше всего времени при реализации должностных обязанностей уходит: «на работу с до- кументами»; «обход (обслуживание) административного участка», «рассмотрение административных протоколов в суде».

Вид профессиональной деятельности, который вызывает негативные переживания: «работа с документами», «некомплект кадров в подразделениях УУП», «участие в совещаниях», «рассмотрение административных протоколов в суде».

Таблица 1

Характеристика доминирующих взаимосвязей служебной деятельности участковых уполномоченных полиции и ее психологических особенностей в оценке экспертами-руководителями

\begin{tabular}{|c|c|c|c|}
\hline $\begin{array}{c}\text { Вид служебной деятельности с } \\
\text { наибольшими временными } \\
\text { затратами }\end{array}$ & $\begin{array}{c}\text { Вид служебной деятельности вы- } \\
\text { зывающие негативные } \\
\text { переживания }\end{array}$ & $\begin{array}{c}\text { Актуальные проблемы, } \\
\text { предопределяющие трудности } \\
\text { в ходе выполнения служебных } \\
\text { обязанностей }\end{array}$ & $\begin{array}{c}\text { Факторы, усиливающие } \\
\text { стрессогенность при выполнении } \\
\text { служебных обязанностей }\end{array}$ \\
\hline $\begin{array}{c}\text { «Работа с документами /отчеты, } \\
\text { справки, рапорта и т.п./» }\end{array}$ & $\begin{array}{c}\text { «Работа с документами /отчеты, } \\
\text { справки, рапорта и т.п./» }\end{array}$ & $\begin{array}{c}\text { «Большой объём } \\
\text { документооборота» }\end{array}$ & $\begin{array}{c}\text { «Неформальное увеличение } \\
\text { продолжительности рабочего дня» }\end{array}$ \\
\hline $\begin{array}{c}\text { Вид служебной деятельности с } \\
\text { наибольшими временными } \\
\text { затратами }\end{array}$ & $\begin{array}{c}\text { Вид служебной деятельности вы- } \\
\text { зывающие негативные } \\
\text { переживания }\end{array}$ & $\begin{array}{c}\text { Актуальные проблемы, } \\
\text { предопределяющие трудности } \\
\text { в ходе выполнения служебных } \\
\text { обязанностей }\end{array}$ & $\begin{array}{c}\text { Факторы, усиливающие } \\
\text { стрессогенность при выполнении } \\
\text { служебных обязанностей }\end{array}$ \\
\hline \multirow[t]{3}{*}{ Участие в совещаниях» } & «Участие в совещаниях» & $\begin{array}{l}\text { «Некомплект кадров } \\
\text { в подразделениях УуП» }\end{array}$ & $\begin{array}{c}\text { «Назначение на должности участ- } \\
\text { ковых уполномоченных полиции } \\
\text { сотрудников женского пола» }\end{array}$ \\
\hline & $\begin{array}{c}\text { «Работа не по своему } \\
\text { направлению» }\end{array}$ & $\begin{array}{c}\text { «Нехватка служебного транспорта } \\
\text { при удаленности } \\
\text { административных участков» }\end{array}$ & \\
\hline & «Планирование рабочего дня» & $\begin{array}{l}\text { «Недостаточный уровень матери- } \\
\text { ально-технического обеспечения» }\end{array}$ & \\
\hline
\end{tabular}

Таблица 2

Характеристика доминирующих взаимосвязей служебной деятельности участковых уполномоченных полиции и ее психологических особенностей в оценке экспертами-участковыми

\begin{tabular}{|c|c|c|c|}
\hline $\begin{array}{c}\text { Вид служебной деятельности с } \\
\text { наибольшими временными } \\
\text { затратами }\end{array}$ & $\begin{array}{c}\text { Вид служебной деятельности } \\
\text { вызывающие негативные } \\
\text { переживания }\end{array}$ & $\begin{array}{c}\text { Актуальные проблемы, } \\
\text { предопределяющие трудности } \\
\text { в ходе выполнения служебных } \\
\text { обязанностей }\end{array}$ & $\begin{array}{c}\text { Факторы, усиливающие } \\
\text { стрессогенность при выполнении } \\
\text { служебных обязанностей }\end{array}$ \\
\hline $\begin{array}{c}\text { «Работа с документами /отчеты, } \\
\text { справки, рапорта и т.п./» }\end{array}$ & $\begin{array}{c}\text { «Работа с документами /отчеты, } \\
\text { справки, рапорта и т.п./» }\end{array}$ & $\begin{array}{l}\text { «Большой объём } \\
\text { документооборота» }\end{array}$ & $\begin{array}{c}\text { «ееформальное увеличение } \\
\text { продолжительности рабочего дня» }\end{array}$ \\
\hline $\begin{array}{c}\text { Вид служебной деятельности с } \\
\text { наибольшими временными } \\
\text { затратами }\end{array}$ & $\begin{array}{c}\text { Вид служебной деятельности } \\
\text { вызывающие негативные } \\
\text { переживания }\end{array}$ & $\begin{array}{c}\text { Актуальные проблемы, } \\
\text { предопределяющие трудности } \\
\text { в ходе выполнения служебных } \\
\text { обязанностей }\end{array}$ & $\begin{array}{c}\text { Факторы, усиливающие } \\
\text { стрессогенность при выполнении } \\
\text { служебных обязанностей }\end{array}$ \\
\hline Участие в совещаниях» & «Участие в совещаниях» & $\begin{array}{c}\text { «Нехватка служебного транспорта } \\
\text { при удаленности } \\
\text { административных участков» }\end{array}$ & $\begin{array}{c}\text { «Режим многозадачности» (большое } \\
\text { количество функциональных задач, в } \\
\text { том числе с несвойственными прямы- } \\
\text { ми обязанностями и порождающие } \\
\text { фрустрационные ситуации) }\end{array}$ \\
\hline $\begin{array}{c}\text { «0бход (обслуживание) админи- } \\
\text { стративных участков» }\end{array}$ & $\begin{array}{l}\text { «Некомплект кадров в } \\
\text { подразделениях УуП» }\end{array}$ & $\begin{array}{l}\text { «Некомплект кадров в } \\
\text { подразделениях УуП» }\end{array}$ & $\begin{array}{c}\text { Увеличение объёма выполняемых } \\
\text { обязанностей из-за некомплекта } \\
\text { кадров в подразделениях УуП» }\end{array}$ \\
\hline $\begin{array}{c}\text { «Рассмотрение административ- } \\
\text { ных протоколов в суде» }\end{array}$ & $\begin{array}{c}\text { «Рассмотрение административ- } \\
\text { ных протоколов в суде» }\end{array}$ & & \\
\hline
\end{tabular}


Среди трудностей в реализации профессиональных обязанностей эксперты-инспектора отметили следующие: «нехватка служебного транспорта», «режим многозадачности», «большой документооборот», «удаленность административных участков» (см. Таблицу 2). Каждый из этих факторов является стрессором.

На фоне проблем, связанных с организацией деятельности участковых уполномоченных полиции на стадии развития стресса - «истощение» могут наблюдаться нарушения деятельности механизмов регуляции и возникновения дезадаптации, что может существенно сказаться на продуктивности труда.

Опрос около 60\% респондентов из ГЭИ показал, что ожидания от выбранной профессией с реальным опытом службы участковым уполномоченным полиции не совпали. Данное обстоятельство имеет негативный подтекст при психоэмоциональной оценке профессиональной деятельности и содержит в себе источник стрессогенности.

Респонденты обеих групп высказали мнение, что больше всего времени при выполнении должностных обязанностей отводится работе с различного вида документами (95\% и 69\% соответственно). Данный вид деятельности является источником негативных переживаний сотрудников ( $25 \%$ и 20\%). Большой документооборот видится экспертами обеих групп как проблема, которая негативно сказывается на результатах служебной деятельности.

Объём служебного времени отводимого для различного вида совещания вызывают негативные переживания. В условиях острого дефицита времени, обширных территорий административных участков, некомплекта кадров в подразделениях - продолжительные и частые совещания создают ситуацию, предрасполагающую к возникновению стрессовой ситуации у сотрудников.

Опрос экспертов в обеих группах показал, что неформальная продолжительность рабочего дня составляет 10-12 часов. Принимая во внимание, что выполнение поставленных задач участковыми уполномоченными полиции осуществляется в условиях дефицита времени, длительного сосредоточения внимания на подготовке необходимой документации, большого объёма переработки информации, высокой степени сложности заданий (при «многозадачности»), а порой и с риском для жизни приводит к риску развития у них профессионального стресса. Систематическая переработка в рабочие дни, а также регулярное привлечение сотрудников к выполнению служебных обязанностей в выходные дни приводит к дистрессу, утомлению и переутомлению, что может негативно сказывается на их психическом и соматическом здоровье.
Одним из эффективных методов профилактики профессионального дистресса может быть использование стресс-менеджмета, под которым понимается способность управлять стрессом.

Основные этапы управления стрессом:

І. Снижение уровня стрессовой ситуации. На этом этапе необходимо:

- описать стрессовую ситуацию, определить стрессоры;

- оценить силу их влияния на рабочий процесс;

- оценить минусы и плюсы в результате негативного развития стрессовой ситуации;

- разработать план по снижению стресс-факторов;

- использовать различные методики и практики для профилактики и выхода из стресса.

II. Использование методов саморегулячии. Саморегуляция - воздействие человека на собственную психику специальными методами с целью управления своим психоэмоциональным состоянием, что позволяет: сдерживать себя в конфликтной ситуации; рационально мыслить при стрессе или кризисе; восстанавливать силы; противостоять невзгодам жизни.

III. Самовостановление - позволяет сформировать устойчивость по отношению к неизбежным стресс-факторам. Основными средствами, способствующими восстановлению организма после переживания стрессовой ситуации являются:

1. мышечная релаксация, аутогенная тренировка;

2. психогигиена (разнообразный досуг, отдых на природе, комфортные условия работы и проживания, социальное общение);

3. соблюдение режима дня, умение планировать деятельность, совмещать периоды труда и отдыха;

4. лечебно-биологические способы (массаж, баня, здоровое питание, водные процедуры);

5. медикаментозные способы на натуральной основе (витамины, травы, ароматические масла).

Следовательно, обобщая все вышесказанное, можно говорить о том, что использование стресс-менеджмента направлено на формирование у участкового уполномоченного полиции:

1. навыков диагностики стрессовых ситуаций, причин, их вызывающих и последствий для профессиональной деятельности;

2. умений использовать приемы снижения негативных воздействий стресс-факторов с учетом индивидуальных особенностей участковых уполномоченных полиции;

3. навыков использования методов индивидуального снятия психического напряжения при планировании и выполнении служебных задач. 


\section{ЛИТЕРАТУРА}

1. Кобозев И.Ю. Психопрофилактика и коррекция профессионального стресса сотрудников ОВД//Вестник Санкт-Петербургского университета МВД России. 2016. - N 1(69). - C. 205-209.

2. Кривова 0.И. Психологические особенности деятельности и эффективные методы подготовки участковых уполномоченных полиции//Современная психология и педагогика: проблемы и решения: сб. ст. по матер. XVII междунар. науч.-практ. конф. № 12(16). - Новосибирск: СибАК, 2018. - С. 131-138.

3. Московская М.С., Котельникова Д.А., Дубинский А.А. Особенности регуляции деятельности у сотрудников следственных органов (клинико-психологический, нейропсихологический и гендерный аспекты)//Психология и право [Электронный ресурс]. - 2017. - Том 7. - N 3. - C. 83-96. - URL: psyandlaw.ru (дата обращения 10.09.2019).

4. Основные стратегии стресс-менеджмента - URL: https://mydocx.ru/10-121462.html (дата обращения 10.09.2019).

5. Патрахина Т.Н., Павлова А.В. Стресс-менеджмент: сущность понятия и процесса//Молодой ученый. - 2015. - N 3. - С. 480-484.

6. Галкина Н.Ю. Психологические методы профилактики стресса в современных условиях // Проблемы современного педагогического образования. Гуманитарно-педагогическая академия (филиал) Федерального государственного образовательного учреждения высшего образования «Крымский федеральный университет имени В.И. Вернадского» (Ялта). - 2018. - С. 403-407.

7. Психологический словарь - URL: http://azps.ru/handbook (дата обращения 03.09.2019).

8. Стресс-менеджмент - URL: http://kak-bog.ru/stress-menedzhment (дата обращения 10.09.2019).

9. Труфанова Т.А. Современные подходы к управлению профессиональными стрессами//Вестник Тамбовского университета. Серия: Гуманитарные науки. 2015. - $N 4$ (144). - C. 77-84.

10. Щербатых Ю.В. Психология стресса и методы коррекции. СПб.: Питер, 2012. - 256 с.

с Чернобродов Евгений Романович (erch70@rambler.ru), Галкина Наталья Юрьевна (galkina55@list.ru).

Журнал «Современная наука: актуальные проблемы теории и практики»

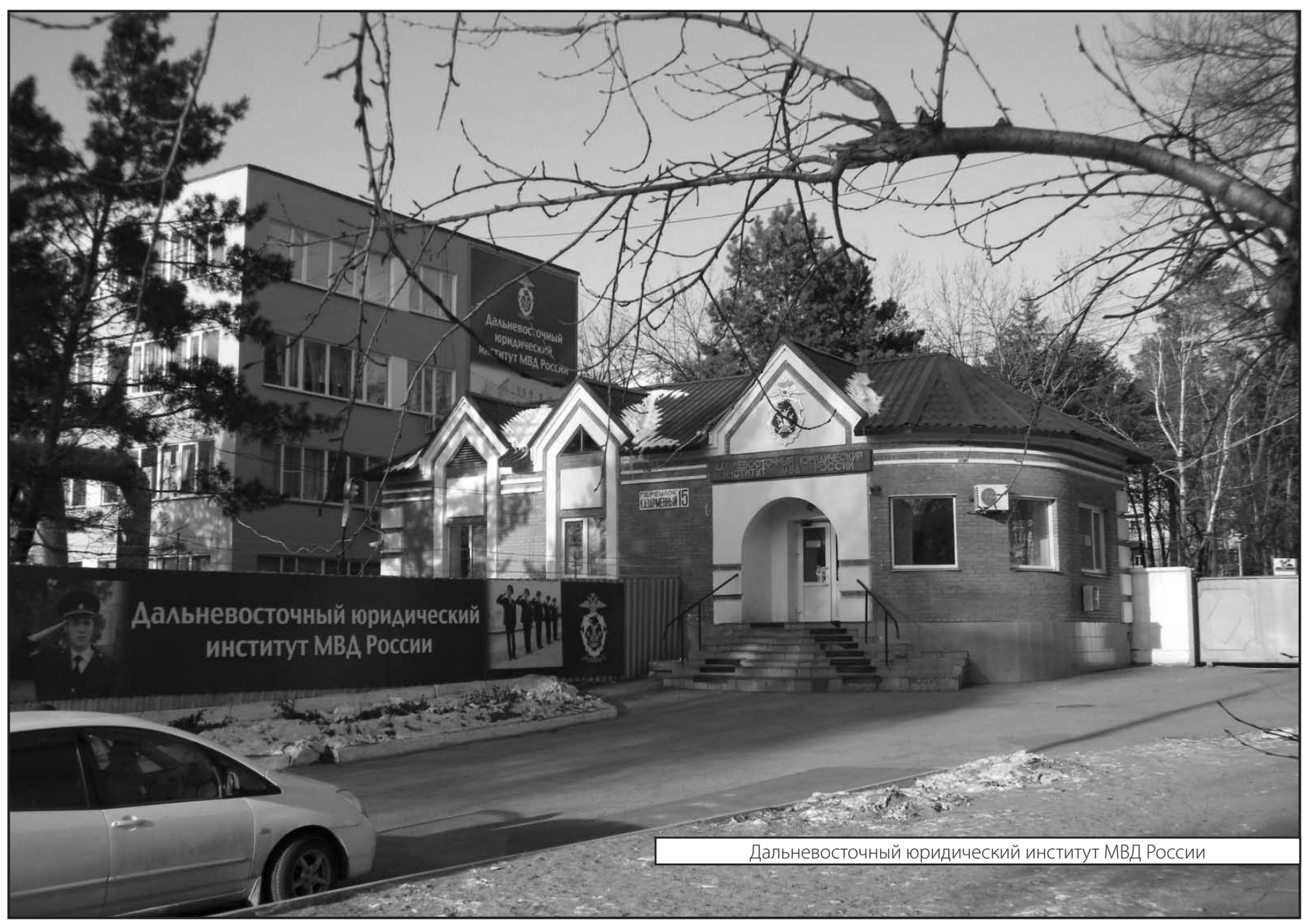

